\title{
Theoretical research of the force field of chlorotrinitromethane in the coordinates $\mathbf{X}_{\delta}{ }^{0}$
}

\author{
(C) Olga S. Averyanova, and Alexander V. Belik*+ \\ Faculty of Chemical Technology and Computing Chemistry. Chelyabinsk State University. Kashyrinych Br. \\ St, 129. Chelyabinsk, 454001. Russia. Phone: +7 (351) 799-70-66. E-mail: belik@csu.ru
}

*Supervising author; ${ }^{+}$Corresponding author

Keywords: $\mathrm{ClC}\left(\mathrm{NO}_{2}\right)_{3}$, chlorotrinitromethane, generalized force constants, coordinates $\mathrm{X}_{\delta}{ }^{0}$, calculations DFT, vibration frequencies.

\begin{abstract}
At present, nitro compounds are widely used in industry and medicine. This necessitates a more thorough study of their specific properties and the construction of theoretical models for their prediction. A special role in this process is given to IR and Raman spectroscopy. However, model calculations are needed to interpret vibrational spectra. This work is devoted to quantum-chemical studies of the force field of the $\mathrm{ClC}\left(\mathrm{NO}_{2}\right)_{3}$ molecule and the solution of the direct spectral problem for the selected object.

The Becke-Lee-Yang-Parr B3LYP method with a hybrid potential of $6-311++\mathrm{G}(3 \mathrm{df}, 3 \mathrm{pd})$, as the most promising, was used as the main approach for the study. In addition, in this paper, as an alternative to chemical (natural) coordinates, new coordinates $\mathrm{X}_{\delta}^{0}$ were chosen, it lets talk about the correctness of the calculations. The calculations presented in this article were implemented using Gaussian and GaussView computer programs designed to calculate a number of molecular properties and characteristics of chemical reactions.

Using the chosen method, in this work, the geometry of the trinitrochloromethane molecule was optimized, the geometric parameters of the compound under study were examined, in particular, were calculated the values of valence angles, dihedral angles, and bond lengths characteristic of the equilibrium configuration of the compound under study. For the first time, generalized force coefficients were obtained for the $\mathrm{ClC}\left(\mathrm{NO}_{2}\right)_{3}$ molecule in the $\mathrm{X}_{\delta}{ }^{0}$ coordinates, which were proposed by L.S. Mayants and G.B. Shaltuper, as universal coordinates in which it is possible to correctly solve the spectral problem. An assessment of the "rigidity" of the chemical bonds of the test compound was carried out. The wave numbers (frequencies of normal vibrations) for the studied molecule in the harmonic approximation are calculated and analyzed. A comparison of the obtained wave numbers with experimental data is given. The results obtained demonstrate a satisfactory agreement between theory and experiment. A general view of the vibrational spectrum of trinitrochloromethane obtained by calculation is presented.
\end{abstract}

\section{References}

[1] H. Feuer. The chemistry of the nitro and nitroso groups. Part 1: translation from English Moscow: Mir. 1975. 536p. (russian)

[2] S.S. Novikov, G.A. Shvehgeymer, V.V. Sevostyanova, V.A. Shlyapochnicov. The chemistry of aliphatic and acyclic compounds. Moscow: Chemistry. 1974. 416p. (russian)

[3] V.A. Shlyapochnikov, D.V. Levchenkov, A.B. Kharitonkin. Vibrational spectra of trinitromethane derivatives. Rus. Chem. Bull. 2001. Vol.50. No.7. P.1173-1180.

[4] N.F. Stepanov, Yu.V. Novakovskaya. Quantum Chemistry Today. Rus. J. Gen. Chem. 2007. Vol.51. No.5. P.5-17. (russian)

[5] W. Kohn. Electronic structure of matter - wave functions and density functionals. UFN (Nobel Lecture 1998). 2002. Vol.172. No.3. P.336-348.

[6] A.D. Becke. Density-functional thermochemistry. III. The role of exact exchange. J. Chem. Phys. 1993. Vol.98. P.5648-5652.

[7] F. Jensen. Introduction to Computational Chemistry. Sec. Ed., Chichester: John Wiley \& Sons Ltd. The Atrium, Southern Gate. 2007. 599p.

[8] A.V. Belik. New aspects of computational chemistry: a monograph. Chelyabinsk: Polygraph-Master. 2015. 200p. (russian)

Kazan. The Republic of Tatarstan. Russia. (C)Butlerov Communications. 2020. Vol.62. No.5. 
[9] D.V. Savchik, V.P. Balykin, A.V. Belik. Solving the vibrational problem using $\mathrm{X}_{\delta}{ }^{0}$ coordinates using an example of an ammonia molecule. Chelyabinsk: Messenger of Chelyabinsk State University. Physics. 2010. No.12(193). Iss.7. P.73-77. (russian)

[10] I.V. Tokmakov, V.A. Shlyapochnikov. Using the theory of hybrid electron density functional (hybrid DFT) to calculate vibrational spectra: nitromethane. Bulletin of the Russian Academy of Sciences. Chemistry. 1997. No.12. P.2106-2109. (russian)

[11] E.B. Wilson, J.C. Decius, P.C. Cross. Molecular vibrations. The theory of infrared and raman vibrational spectra. translation from English. Moscow: Foreign Literature Publishing House. 1960. 358p. (russian)

[12] L.S. Mayants. Theory and Calculation of Molecular Vibrations. Moscow: USSR Academy of Sciences. 1960. 526p. (russian)

[13] L.S. Mayants, G.B. Shaltuper. A new approach to the full calculation of the vibrations of any molecules. USSR Academy of Sciences report. 1972. No.206. P.657-660. (russian)

[14] L.S. Mayants, G.B. Shaltuper. General methods of analysing molecular vibrations. J. Mol. Struct. 1975. Vol.24. P.409-431.

[15] M.J. Frisch, G.W. Trucks, H.B. Schlegel et al. Gaussian 09, Revision A.02. Gaussian, Inc., Wallingford CT. 2009.

[16] E.V. Butyrskaya. Computer Chemistry: Fundamentals of Theory and Work with Gaussian and GaussView Programs. Moscow: SOLON-PRESS. 2011. 224p. (russian)

[17] E.I. Fedotova, and A.V. Belik. Nitrocompounds: structure, force coefficients in coordinates $\mathrm{X}_{\delta}{ }^{0}$ and the frequencies of normal vibrations of $\mathrm{NO}_{2}$-group. Butlerov Communications. 2012. Vol.31. No.9. C.2935. ROI-jbc-02/12-31-9-29

[18] E.I. Fedotova, A.V. Belik. Effect of the number of nitro groups in a molecule on the force fields of nitroalkanes. Chelyabinsk: Messenger of Chelyabinsk State University. Physics. 2011. No.39. Iss.12. P.42-47. (russian) 